\title{
Tecnologia e sustentabilidade ambiental: desafios e possibilidades para os países periféricos
}

\author{
Maurício A. Serra* \\ Gustavo Inácio de Moraes ${ }^{* *}$
}

\section{Introdução}

A questão ambiental começou a ser efetivamente debatida nos anos 70 com a publicação do livro "Os Limites do Crescimento" (Meadows \& Meadows, 1972), que continha uma crítica contundente ao modelo de crescimento econômico vigente na medida em que a busca incessante por crescimento geraria inevitavelmente sérios problemas sociais e ambientais. Esse debate acerca das relações entre crescimento e meio ambiente contribuiu para a formulação do conceito de desenvolvimento sustentável, em cuja noção está embutido o reconhecimento de dois importantes aspectos: o de que o progresso tecnológico flexibiliza os limites ambientais, embora não os elimine, e o de que o crescimento econômico é uma condição importante e necessária, mas não suficiente para a completa eliminação da pobreza e das desigualdades sociais.

O ponto capital, no entanto, reside na capacidade do progresso científico e tecnológico superar indefinidamente os obstáculos impostos pela disponibilidade de recursos naturais, de modo a propiciar uma contínua expansão econômica dos países. Esta questão se torna ainda mais complexa em termos de viabilização da sustentabilidade quando se leva em consideração a existência de um padrão norte-sul de consumo e de um gap tecnológico entre os países centrais e periféricos. Neste sentido, o objetivo deste artigo é discutir o papel da tecnologia na viabilização da sustentabilidade ambiental. Para tanto, o presente texto está estruturado em quatro seções: a primeira apresenta a discussão do comportamento da degradação ambiental em função do desenvolvimento econômico. $\mathrm{Na}$ segunda seção são comparados os níveis de consumo nos países centrais e periféricos e os seus impactos sobre o desenvolvimento sustentável. Já a terceira seção tem como discussão central a forma pela qual a tecnologia poderá auxiliar na busca por uma sustentabilidade ambiental. Por fim, na quarta e última seção alguns comentários são tecidos.

\footnotetext{
* Professor do Departamento de Economia e do Programa de Pós-Graduação em Desenvolvimento Econômico da Universidade Federal do Paraná (PPGDE/UFPR). Endereço eletrônico: serra@ufpr.br

** Doutorando em Economia Aplicada na ESALQ-USP. Endereço eletrônico: gimoraes@,esalq.usp.br
} 


\section{Desenvolvimento versus Degradação Ambiental: a Curva Ambiental de} Kuznets

De forma análoga à proposição de Kuznets (1955), Grossman e Krueger (1991) e, posteriormente, o World Bank (1992) e Shafik e Bandyopahyay (1992) propuseram a Curva Ambiental de Kuznets cuja variável dependente, que no trabalho original de Kuznets é a desigualdade de renda, é alterada para a degradação ambiental medida pela poluição, sendo a renda per capita mantida como variável independente. Desse modo foi estabelecida uma relação não-linear característica (U invertido) em que a partir de um determinado nível de renda per capita a degradação ambiental se tornaria declinante.

A razão deste comportamento seria justificada pelo fato de que num processo de desenvolvimento econômico seria inevitável que agressões ao meio ambiente ocorressem. Entretanto, este quadro seria revertido na medida em que a renda continuaria se elevando, posto que as pessoas adquiririam um maior grau de consciência sobre os danos ambientais gerados pelo processo de desenvolvimento. Uma primeira explicação estaria assentada na exigência de regulamentos mais firmes, o que premiaria o consumo de produtos que fossem ambientalmente inofensivos ou que fossem produzidos através de processos que levassem em conta as externalidades negativas sobre o ecossistema. Uma segunda explicação seria a de que as empresas adotariam tecnologias que privilegiassem processos limpos em função do custo e da produtividade apresentadas, sendo este o caso das novas fontes energéticas e da biotecnologia. A terceira explicação residiria no fato de que ao ocorrer elevação de renda, o perfil aquisitivo da região se modificaria a ponto dos bens responsáveis por impactos ambientais fossem importados e não mais produzidos em seu território (Panayotou, 1997; Bousquet \& Favard, 2000).

Uma limitação que se coloca em relação à Curva Ambiental de Kuznets é que os estudos tomam como critério a ser adotado variáveis que têm caráter cumulativo e não apenas passageiro. Um bom exemplo é o estudo de Shafik e Bandyopadhyay (1992), que adota o desmatamento como variável a ser explicada e que, portanto, teria que apresentar o formato de $\mathrm{U}$ invertido. Todavia, os autores desconsideraram o fato de que o desmatamento tem sido irreversível, já que as fronteiras agrícolas e urbanas têm se expandido de forma contínua. Assim não é surpresa que ambos os autores não tenham obtido a curva de Kuznets para o critério desmatamento. Por isso, é válido alertar para um exame mais atento a respeito do critério utilizado, detalhando-o e classificando-o inicialmente como de efeitos permanentes ou 
de efeitos passageiros, sendo exemplo destes últimos a poluição das águas e do ar ou até mesmo a ocorrência de doenças respiratórias.

Em contraposição, Grossman e Krueger (1995) foram os que obtiveram resultados mais robustos na investigação da Curva Ambiental de Kuznets, cuja existência foi validada para os indicadores de $\mathrm{SO}_{2}$ nas partículas de ar para fumaça, oxigênio dissolvido na água, demanda biológica por oxigênio na água e nas partículas de coliformes fecais na água. Nos cinco critérios em que a Curva Ambiental de Kuznets foi verificada, o ponto onde houve a inversão de relação positiva para a negativa esteve situado entre US\$2,7 mil e US\$ 8 mil, indicando a possibilidade de países ainda em estágio intermediário de desenvolvimento alcançarem trajetória de declínio na degradação ambiental.

\section{Padrões de Consumo Norte e Sul: O hiato poderá ser vencido?}

De um modo geral, políticas públicas têm sido adotadas por governos de diversos países na busca por desenvolvimento sustentável. Contudo, a forte diferenciação nos padrões de consumo permanece até os dias de hoje. Por exemplo, examinando-se o consumo per capita de energia pode-se notar uma diferença acentuada entre as nações mais ricas e as nações mais pobres (tabela1).

Tabela 1. Consumo de Energia per Capita (Toneladas Equivalentes de Petróleo)

\begin{tabular}{llll}
\hline Grupo de Países & $\mathbf{2 0 0 0}$ & $\mathbf{2 0 0 1}$ & $\mathbf{2 0 0 2}$ \\
\hline OCDE & 5,46 & 5,41 & 5,42 \\
América Latina e Caribe & 1,17 & 1,16 & 1,15 \\
Baixa e Média Renda & 0,96 & 0,96 & 0,99 \\
\hline
\end{tabular}

Fonte: World Bank, 2005

Um outro bom exemplo é o lançamento de toneladas de $\mathrm{CO}_{2}$ per capita na atmosfera. Em 2000, os países da OCDE lançavam na atmosfera cerca de 12,45 toneladas per capita de $\mathrm{CO}_{2}$ anuais, enquanto os países da América Latina lançavam “apenas” 2,66 toneladas e os países de baixa e média renda em seu conjunto lançavam 2,45 toneladas (World Bank, 2005). Ao mesmo tempo, a população dos países da OCDE representa aproximadamente apenas um sexto da população mundial e com uma taxa de fertilidade inferior aos países de baixa e média renda (World Bank, 2005). Este quadro torna-se mais grave quando se leva em consideração o fato de que significativa parcela da população dos países em desenvolvimento vive no setor rural, cujas características ainda são a subsistência e o acesso a poucos bens de consumo. 
As dificuldades dos países periféricos em obter o mesmo padrão de desenvolvimento dos países mais avançados são acentuadas. Novas soluções técnicas terão obrigatoriamente que ser adotadas e/ou o padrão de consumo da sociedade deverá resultar em elementos diferenciados de consumo dos recursos. Desse modo, qualquer discussão que envolva um maior acesso aos bens necessários e/ou de luxo por parte das populações dos países periféricos passa por soluções tecnológicas, sendo o principal problema a necessidade de recursos de grande parte dos países periféricos para desenvolver e aplicar na produção tais tecnologias. Quando as tecnologias já existem, o conhecimento e a patente são propriedades de um país central, acarretando em maiores dificuldades com o balanço de pagamentos. Um exemplo deste fenômeno é encontrado no indicador de investimento direto estrangeiro. Em 2003, os países periféricos receberam US\$ 165 bilhões, ao passo que os países centrais receberam US\$ 390 bilhões (World Bank, 2005), o que significa dizer que os já descapitalizados países periféricos se encontram numa situação ainda mais complicada para conseguir almejar um novo patamar tecnológico.

Qualquer que seja o critério utilizado para mostrar o fosso existente entre países centrais e periféricos, eles tornam evidentes o diferencial de consumo e o potencial impacto que haveria sobre o planeta no caso das populações dos países periféricos terem o mesmo nível de consumo das populações dos países ricos. Um bom exemplo de como os padrões de consumo podem contribuir para dificultar o alcance da sustentabilidade é dado por Motta, Ferraz e Young (2001), que ilustram com dados da POF como a posse de bens variou entre 1987 e 1996 no Brasil. Em relação aos automóveis, houve um crescimento de 112\% na aquisição destes bens nas famílias que recebiam entre 2 e 3 salários mínimos de renda, ao passo que nas famílias com 30 ou mais salários houve um aumento de apenas 21\%. O mesmo padrão é verificado para o caso de refrigeradores (57\% e 21\%, respectivamente) e televisores (288\% e 24\%, respectivamente). Uma parte da explicação pode ser atribuída ao Plano Real, que estabilizou o nível de preços e, consequentemente, fez com que a população menos abastada tivesse o seu padrão de aquisição protegido.

\section{Tecnologia e Sustentabilidade Ambiental}

O objetivo desta seção é mostrar dois caminhos acerca da evolução tecnológica voltada para a mitigação do uso dos recursos naturais. O primeiro desdobra-se em duas vertentes: 1) as inovações institucionais que estimulam novas tecnologias voltadas para a sustentabilidade ambiental e 2) o desenvolvimento dos setores de tecnologia de comunicações e microeletrônica colocados como novos paradigmas. Ambas as vertentes são 130 
predominantes nos países centrais, ao passo que a adoção de uma tecnologia intermédia seria predominante nos países periféricos.

\subsection{Países Centrais}

Boa parte das análises do desempenho das tecnologias ainda se concentra no acompanhamento nas diferentes etapas de adoção de um novo processo produtivo ou um novo produto. A avaliação estaria centrada em diferentes graus: alteração, melhoramento, diferenciação, transformação e novidade. Com a preocupação da sustentabilidade ambiental, a avaliação se faria através do melhoramento introduzido pela tecnologia. Neste sentido, os novos paradigmas superam os antigos paradigmas produtivos, que eram baseados fundamentalmente no padrão fordista/ taylorista, cujos pressupostos eram o da produção em massa e o do consumo de matérias-primas em larga escala, sendo a difusão da eletricidade e o motor à combustão as transformações tecnológicas que viabilizaram esse padrão.

Os novos paradigmas estão estruturados em novas formas organizacionais das firmas que modificam por completo o processo produtivo. $O$ processo organizacional das firmas está concentrado na configuração em rede e a tecnologia passa, neste momento, a assumir um caráter de causa e também de conseqüência nas transformações. Neste novo cenário, a firma dispõe de variadas opções tecnológicas (Tigre, 1998) e a configuração em "rede" da firma vem a ser um fator decisivo. Esta configuração é que possibilita a firma maximizar as fontes de informação e ter novas gestões sobre a tecnologia e sobre os fatores de produção, como a mão de obra. Por sua vez, a "rede" estabelecida pela firma assume diversos tipos de configuração ${ }^{37}$, o que significa que as mudanças tecnológicas tendem a ter repercussões maiores e mais duradouras sobre o crescimento econômico na medida em que parte da importância das indústrias que ofertam insumos para vários segmentos atuaria reduzindo custos e aumentando a oferta.

Em paralelo, com a transformação produtiva concentrando-se em setores mais eficientes e com repercussões diferentes sobre o processo produtivo, a sustentabilidade ambiental tende a ser favorecida. A busca por uma maior maximização no uso dos recursos tende a melhorar o aproveitamento dos recursos naturais e o maior peso dos setores microeletrônicos e de comunicações tende a diminuir a intensidade no uso dos recursos naturais.

${ }^{37}$ As que mais se destacam seriam: alianças estratégicas, redes hierarquizadas e redes não-hierarquizadas. 
A análise de Jorgensen, Christensen e Lau (1973), por exemplo, faz uma releitura da função de produção tradicional. A função de produção tradicional destaca o papel do capital e do trabalho na obtenção do produto. A nova função de produção proposta incorpora a necessidade de energia e materiais no processo produtivo. Assim sendo, há o reconhecimento, ao menos teoricamente, da participação e da importância dos recursos, principalmente naturais, na obtenção do produto econômico.

A segunda parte, talvez mais relevante, é que este processo associa-se a fatores organizacionais, socioculturais e institucionais. A análise de Dosi (1988), por exemplo, destaca o papel das macro-instituições em contraponto às micro-instituições. As primeiras operariam no âmbito das normas e regulamentações e até mesmo na política econômica, enquanto as segundas estariam ligadas ao processo produtivo no interior e na rotina da produção. Nesta linha de raciocínio, Foxson, Makuch, Mata e Pearson (2004) destacam a importância da adoção, por parte das instituições públicas, de incentivos que beneficiem o desenvolvimento de políticas de geração de tecnologia sustentável dentro dos SNI (Sistemas Nacionais de Inovação). Aqui, efetivamente destacam-se os papéis da PD\&D (Pesquisa, Desenvolvimento e Demonstração) e das demais fases da vida da tecnologia: desenvolvimento experimental, indústria crescente e indústria madura. Os autores concluem que o papel das políticas públicas de inovação é decisivo e devem ser orientados para o longo-prazo.

\subsection{Países Periféricos}

Nos países periféricos, a difusão das novas configurações da firma é limitada, sendo duas as explicações básicas para este comportamento: 1) as indústrias (microeletrônica e comunicações) que lideram este processo ainda se encontram em um estágio mais atrasado nesses países e 2) o fraco desempenho das instituições nestes países e, ao mesmo tempo, o mercado consumidor pequeno como um fator de limitação, obrigando as indústrias com novos paradigmas tecnológicos a competir, em condições desfavoráveis, no mercado internacional.

Os países periféricos ausentes e retardatários nestas mudanças de caráter tecnológico poderiam trilhar um caminho autônomo, respeitando suas limitações. Este caminho seria o da tecnologia intermédia, apontado por Schumacher (1977). A concepção do conceito de tecnologia intermédia envolveu uma preocupação com as populações que não eram participantes das vantagens do desenvolvimento econômico, através de seus instrumentos mais modernos, mas que por outro lado ao ingressarem no consumo buscassem um padrão 
mais correto em termos de aproveitamento dos recursos. Portanto, se adotado o nível correto de tecnologia não haveria confronto entre recursos escassos e desenvolvimento econômico.

Uma importante abordagem da adoção da tecnologia intermédia é o direcionamento para as indústrias mais propensas ao desenvolvimento. Todavia, a escolha estaria submetida a dois fatores de risco e de grande interesse para os países em desenvolvimento: que fosse poupadora de recursos econômicos e de recursos naturais. A implementação poderia ser realizada em diferentes regiões, respeitando os limites impostos pelas potencialidades locais.

Uma maneira ao alcance dos países periféricos seria não apenas reconhecer as limitações do salto brutal que se constitui a transição de um padrão de consumo mais baixo para um padrão de consumo mais elevado, mas também preparar essa população excluída para ingressar de forma adequada no processo de desenvolvimento econômico e de consumo, sem que haja um aumento explosivo da dilapidação de recursos naturais.

\section{Considerações Finais}

Percebendo-se a necessidade do crescimento econômico e da extensão deste para os países periféricos, o impacto sobre o meio ambiente poderá se ampliar intensamente. A hipótese estabelecida pela Curva Ambiental de Kuznets de que o nível crescente de renda per capita acaba por determinar uma diminuição no ritmo da degradação parece estar mais associada à incorporação de padrões tecnológicos do que à dinâmica do crescimento econômico.

Os padrões de consumo dos países desenvolvidos quando reproduzidos para os países em desenvolvimento, tornam impossível a manutenção do ecossistema global em qualquer equilíbrio. Contudo, não se pode negar às populações dos países em desenvolvimento a oportunidade de acessar os bens de consumo e o conforto que as populações dos países desenvolvidos possuem.

A tecnologia seria, portanto, a principal resposta para o alcance da sustentabilidade na medida em que proporcionasse que o consumo de bens e a produção econômica fossem orientados para padrões poupadores de recursos naturais. Todavia, mesmo estas tecnologias encontram-se predominantemente nos países centrais, que podem ou não transferi-las para os países periféricos. Neste caso, estes últimos necessitariam desenvolver tecnologias próprias para evitar uma maior dependência econômica dos países centrais. A tecnologia intermédia poderia se constituir num caminho alternativo para este grupo de países ainda com necessidades de desenvolvimento econômico. 


\section{Referências Bibliográficas}

Dosi, G. (1988), "Institutions and Markets in a Dynamic World", The Manchester School, vol. LVI, nº 2 , June.

Foxson, T.; Makuch, Z.; Mata, M. \& Pearson, P. (2004), "Innovation Systems and Policy-Making Processes for the Transition to Sustainability". In: K. Jacob; M. Binder \& A. Wieczorek (eds.), Governance for Industrial Transformation, Berlin: Environmental Policy Research Centre, p. 96-112.

Grossman, G. M. \& Krueger, A. B. (1991), "Environmental Impacts of a North American Free Trade Agreement", NBER Working Paper no 3914.

Jorgensen, D. W.; Christensen, L. R. \& LAU, L. J. (1973), "Transcendental Logarithmic Production Frontiers", The Review of Economics and Statistics, vol. 55, p. 28-45.

Kuznets, S. (1955), "Economic Growth and Income Inequality", American Economic Review, vol. XLV, n 1, p. 1-28.

Meadows, D. \& Meadows, D. (1972), The Limits of Growth: a report for the Club of Rome's project on the predicament of Mankind, London: Potomac.

Motta, R. S. da; Ferraz, C. \& Young, C. E. F. (2001), Making Long-Term Growth More Sustainable: Brazil country case-study, final report for the project "Making Long-Term Growth More Sustainable" financed by the World Bank, mimeo.

Panayotou, T. (1997), "Demystifying the Environmental Kuznets Curve: turning a black box into a policy tool", Environment and Development Economics, vol.2, n ${ }^{\circ}$ 4, p. 465-484.

Ribault, J. M.; Martinet, B. \& Lebidois, D. (1995), A Gestão das Tecnologias, Lisboa: Dom Quixote.

Schumacher, E. F. (1983), O Negócio é Ser Pequeno: um estudo de economia que leva em conta as pessoas, Rio de Janeiro: Zahar.

Shafik, N. \& Bandyopadhyay, S. (1992), Economic Growth and Environmental Quality: time series and cross country evidence, Washington, D. C.: The World Bank. p. 67-111.

Tigre, P. B. (1998), "Inovação e Teorias da Firma em Três Paradigmas", REC, no 3,

World Bank (1992), The World Bank Development Report 1992: development and the environment, New York: Oxford University Press.

World Bank (2005), World Development Indicators, Washington, D. C.: The World Bank. 